\title{
KAPASITAS GESER BALOK BETON BERTULANG HVFA MEMADAT SENDIRI DENGAN KADAR FLY ASH 50\% TERHADAP BETON NORMAL
}

\author{
Ilham Aryono ${ }^{1)}$, Agus Setiya Budi ${ }^{2}$, Halwan Alfisa Saifullah ${ }^{3)}$ \\ 1) Mahasiswa Prodi Teknik Sipil, Fakultas Teknik, Universitas Sebelas Maret \\ 2),3) Pengajar Prodi Teknik Sipil, Fakultas Teknik, Universitas Sebelas Maret \\ J1. Ir. Sutami 36A, Kentingan Surakarta 57126; Telp 0271-634524. \\ Email: ilhamaryono1@gmail.com
}

\begin{abstract}
The use of alternative materials to replace cement as a concrete constituent is increasingly found. One of them is fly ash. Fly ash is the residual combustion of coal in the form of fine particles that contain a lot of silica (SiO2). The content of silica is very suitable for the reaction of concrete formation chemical reactions. In this study, the level of cement content will be replaced by $50 \%$ fly ash in the manufacture of high volume steel reinforced concrete compact compact concrete (HVFA-SCC) and compared to normal concrete. The test beam measures $10 \mathrm{~cm} \times 15 \mathrm{~cm}$ with a length of $150 \mathrm{~cm}$. The test was carried out by shear capacity test at the age of 28 days by using a loading frame test equipment and installing a dial gange at the midpoint of the span and loading point at 1/3 the length of the beam. The results of this test are the value of acceptable load and deflection until they experience shear failure. Based on this study, the value of HVFA-SCC shear capacity is greater than normal concrete, which is equal to $32.125 \mathrm{kN}$ for HVFA-SCC and at $20.500 \mathrm{kN}$ for normal concrete.
\end{abstract}

Keywords: fly ash, HVFA-SCC, shear capacity.

\begin{abstract}
Abstrak
Penggunaan material alternatif pengganti semen sebagai penyusun beton semakin banyak ditemukan. Salah satunya adalah fly ash. Fly ash adalah sisa pembakaran batubara berupa partikel halus yang mengandung banyak silica (SiO2). Kandungan silica sangat cocok untuk reaksi kimia pembentukan beton. Pada penelitian ini, kadar kandungan semen akan diganti dengan fly ash sebanyak 50\% pada pembuatan balok beton bertulang baja high volume fly ash self compacting concrete (HVFA-SCC) dan dibandingkan dengan beton normal. Balok uji berukuran $10 \mathrm{~cm}$ x $15 \mathrm{~cm}$ dengan panjang $150 \mathrm{~cm}$. Pengujian yang dilakukan adalah uji kapasitas geser pada umur 28 hari dengan menggunakan alat uji loading frame dan memasang dial gauge di titik tengah bentang dan titik pembebanan pada $1 / 3$ panjang balok. Hasil dari pengujian ini adalah nilai beban dan lendutan yang dapat diterima hingga mengalami keruntuhan geser. Berdasarkan penelitian ini, nilai kapasitas geser HVFA-SCC lebih besar dibandingkan beton normal, yaitu sebesar 32,125 kN untuk HVFA-SCC dan sebesar 20,500 kN untuk beton normal.
\end{abstract}

Kata Kunci : fly ash, HVFA-SCC, kapasitas geser.

\section{PENDAHULUAN}

Pembangunan infrastruktur di Indonesia semakin banyak dan pesat mengikuti perkembangan jaman. Beton merupakan salah satu material dalam pembangunan infrastruktur yang dari tahun ke tahun semakin berkembang teknologi dan inovasinya. Jenis beton bermacam-macam, salah satu contohnya adalah beton memadat mandiri atau Self Compacting Concrete (SCC). Self Compcating Concrete (SCC) memiliki sifat yang memudahkan dalam hal workability karena beton segarnya lebih cair daripada hasil pembuatan beton segar pada beton normal. Campuran $S C C$ juga berbeda, yaitu pada penggunaan semen yang lebih banyak, penggunaan superplasticizer, yaitu zat kimia yang mampu meningkatkan workability beton. Jumlah penggunaan semen yang banyak pada SCC merupakan hal yang harus diperhatikan, karena dengan produksi semen yang berlebih dapat menyebabkan kerusakan lingkungan berupa efek rumah kaca dan pemanasan global. Pada tahun 2016, produksi semen dunia sekitar 2,2 miliar ton karbon dioksida $\left(\mathrm{CO}_{2}\right)$, setara dengan sekitar $8 \%$ emisi karbon dioksida $\left(\mathrm{CO}_{2}\right)$ dunia, menurut lembaga penelitian Chatham House. Untuk mengatasi masalah lingkungan tersebut, maka dilakukan beberapa penelitian tentang bahan atau material pengganti semen. Salah satu contoh pengganti semen adalah fly ash. Fly ash adalah limbah hasil pembakaran batu bara pada tungku pembangkit listrik tenaga uap yang berbentuk halus, bundar, dan bersifat pozolanik (SNI, 2002). Keunggulan fly ash dalam campuran beton antara lain, meningkatkan workability, kepadatan, dan durabilitas beton, serta mengurangi penyusutan, segregasi, dan bleeding pada beton (ACI, 1993). Pemakaian fly ash sebagai filler pada beton karena fly ash sangat halus (kurang dari $10 \mu \mathrm{m}$ ) sehingga dapat mengisi celah-celah pada beton (Desi, 2016). Penelitian dan penggunaan tentang beton fly ash dalam jumlah banyak atau lebih dikenal dengan High Volume Fly Ash Concrete (HVFAC) masih jarang. High Volume Fly Ash Concrete adalah beton dimana setidaknya 50\% jumlah semen sebagai bahan pengikat digantikan fly ash (Solikin dan Setiawan, 2014). Penambahan fly ash pada SCC juga mampu menambah workabilitas dari beton tersebut. Selain itu, biaya 
produksi juga dapat diperkecil karena harga fly ash yang relatif sangat murah jika dibandingkan dengan semen (Hamka, 2008). Fly ash sebanyak 50\% sebagai pengganti semen dalam produksi SCC menghasilkan kuat tekan yang setara dengan beton normal pada beton mutu tinggi (Mulyanto Tri, 2015).

Beton memiliki kuat tekan yang sangat baik sedangkan untuk kuat tarik beton cenderung lemah. Dalam pengaplikasiannya, beton diberi tulangan baja untuk mengatasi kelemahan akan kuat tariknya, karena baja sendiri memiliki kuat tarik yang tinggi. Penelitian ini akan mengkaji seberapa besar kapasitas geser balok beton bertulang High Volume Fly Ash - Self Compacting Concrete (HVFA - SCC) dengan kadar fly ash $50 \%$ dan kemudian akan dibandingkan dengan balok beton normal pada umur 28 hari.

\section{LANDASAN TEORI \\ High Volume Fly Ash (HVFA)}

High Volume Fly Ash Concrete adalah beton dimana setidaknya 50\% jumlah semen sebagai bahan pengikat digantikan fly ash (Solikin dan Setiawan, 2014). High Volume Fly Ash Concrete memiliki nilai kuat tekan yang rendah pada awal umur beton namun akan terjadi peningkatan kekuatan yang cukup signifikan ketika berumur 28 dan 56 hari (Herbudiman dan Akbar, 2015). Kelebihan beton tersebut adalah ramah lingkungan, ekonomis, memperlambat setting time, meningkatkan workability, durability. (Stefanus dan Howard, 2010).

\section{Self Compacting Concrete (SCC)}

Self-Compacting Concrete (SCC) pertama kali dikembangkan di Jepang sekitar tahun 1980-an untuk mencapai struktur beton yang memiliki daya tahan tinggi. SCC adalah campuran beton yang mampu memadat sendiri tanpa menggunakan alat pemadat atau mesin penggetar atau vibrator (Sholihin, 2012). Beton segar SCC memiliki fluiditas tinggi yang dapat mengalir dan mengisi ruang-ruang dalam cetakan dengan sedikit atau tanpa proses getaran (Okamura dan Ouchi 2003). Penggunaan admixture superplastiziser yang memungkinkan penurunan rasio air-semen (w/c) hingga nilai w/c $=0,3$ atau lebih kecil (Juvas, 2004). Menurut Hela dan Hubertova (2006) kemampuan mengalir dengan tingkat ketahanan terhadap segregasi yang tinggi SCC disebabkan oleh penggunaan superplastiziser. Perbedaan utama antara SCC dengan beton konvensional adalah porsi komponen halus yang lebih banyak dan mengurangi porsi dan ukuran agregat kasar. Komponen halus akan mengurangi segregasi dan meningkatkan kohesivitas campuran.

\section{High Volume Fly Ash - Self Compacting Concrete (HVFA-SCC)}

HVFA-SCC adalah perpaduan teknologi antara HVFAC dan SCC dimana pembuatan beton dibuat dengan kadar fly ash minimal 50\% dari berat binder dan memiliki sifat-sifat beton segar sama seperti SCC biasa. Penggunaan fly ash dimaksudkan untuk meningkatkan workability beton segar dan juga mengisi rongga-rongga yang ada pada beton. HVFA - SCC dapat mengalir dan memadat dengan memanfaatkan berat sendiri, sehingga tidak diperlukan proses pemadatan dengan menggunakan alat (Karina, 2018).

\section{Kapasitas Geser Balok}

Pengaruh-pengaruh geser yang ditumbulkan merupakan akibat dari torsi dan kombinasi torsi dengan lentur (Chukia Wang dan Charles G. Salmon, 1983).

Berdasarkan persamaan Niwa (1986), menghitung nilai kuat geser adalah sebagai berikut :

$$
\mathrm{V}_{\mathrm{C}}=0.2 \mathrm{fc}^{1 / 3}(\mathrm{~d} / 1000)^{-1 / 4}\left(100 \mathrm{p}_{\mathrm{s}}\right)^{1 / 3}(0.75+1.4 /(\mathrm{a} / \mathrm{d})) \mathrm{bd}
$$

Pada sampel uji penelitian ini hanya menggunakan tulangan utama tanpa adanya tulangan sengkang, hal ini bertujuan untuk memastikan pada saat pengujian balok akan mengalami gagal geser. Untuk itu kekuatan geser nominal $\left(V_{n}\right)$ hanya dari kontribusi kekuatan geser beton $\left(V_{c}\right)$.

$\mathrm{V}_{\mathrm{u}} \leq \phi \mathrm{V}_{\mathrm{n}}$

Karena $V_{\mathrm{s}}=0$ maka,

$$
\mathrm{V}_{\mathrm{n}}=\mathrm{V}_{\mathrm{s}}+\mathrm{V}_{\mathrm{c}}
$$

$\mathrm{V}_{\mathrm{n}}=\mathrm{V}_{\mathrm{c}}$

Menurut SNI T-15-1991-03 Vc dapat dihitung menggunakan persamaan:

$$
V_{c}=1 / 6 \sqrt{f^{\prime} c} b_{w} d
$$

\section{METODE}

Metode penelitian yang digunakan dalam penelitian ini adalah metode eksperimental. Benda uji yang digunakan adalah balok beton bertulang berukuran $10 \mathrm{~cm}$ x $15 \mathrm{~cm}$ dengan panjang $150 \mathrm{~cm}$. Balok uji dibagi menjadi balok HVFA-SCC dengan kadar fly ash $50 \%$ dan balok beton normal. Pengujian pada umur 28 hari. Model benda uji ditampilkan dalam Gambar 1. 


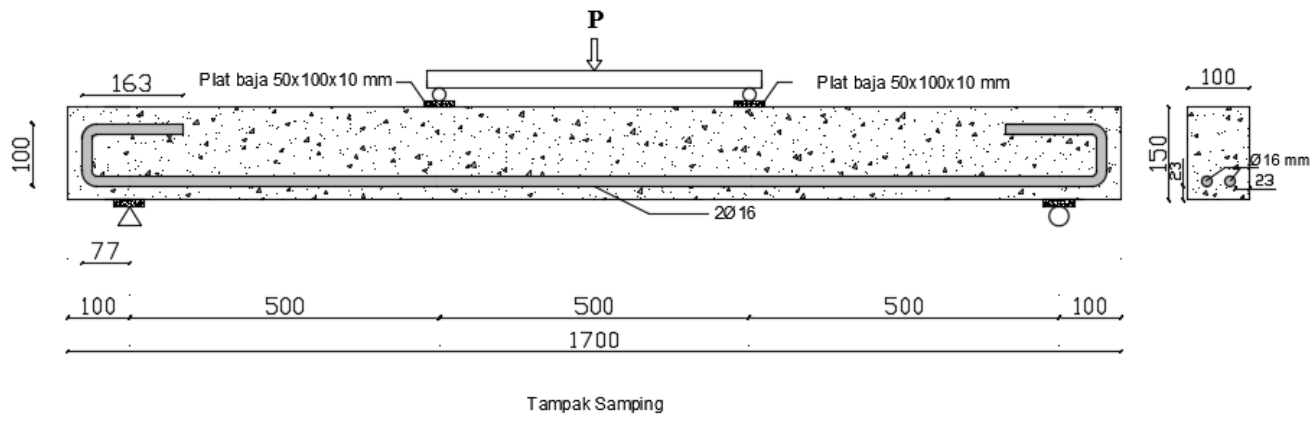

Gambar 1. Model Benda Uji Balok Geser

Pengujian dilakukan dengan memberikan beban pada 2 titik pembebanan di 1/3 bentang dan pemasangan dial gauge pada titik tengah bentang dan titik pembebanan untuk membaca nilai lendutan. Setting up alat pengujian ditampilkan dalam Gambar 2.

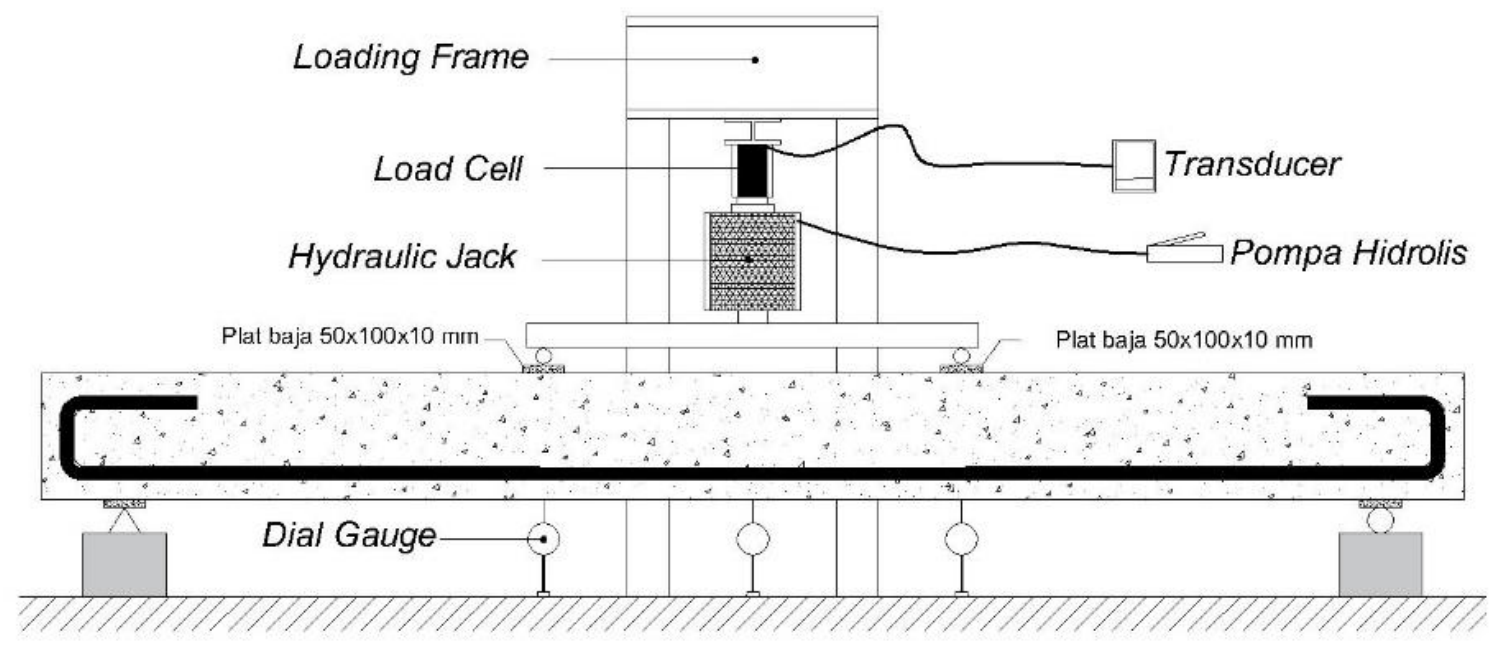

Gambar 2. Setting Up Alat Pengujian Balok (Standar ASTM Vol. 04.02)

\section{HASIL DAN PEMBAHASAN}

\section{Hasil Pengujian Bahan}

Pengujian agregat halus berupa pengujian absorbtion, apparent specific gravity, bulk specific gravity, kandungan zat organik, kandungan lumpur, dan bulk spesific SSD. Hasil pengujian ditampilkan dalam Tabel 1.

Tabel 1. Hasil Pengujian Agregat Halus

\begin{tabular}{lccc}
\hline \multicolumn{1}{c}{ Jenis Pengujian } & Hasil Pengujian & Standar & Keterangan \\
\hline Absorbtion & $1,9368 \%$ & - & - \\
\hline Apparent Specific Gravity & $2,6272 \mathrm{gr} / \mathrm{cm}^{3}$ & - & - \\
\hline Bulk Specific Gravity & $2,500 \mathrm{gr} / \mathrm{cm}^{3}$ & - & - \\
\hline Kandungan Zat Organik & Kuning Muda & Kuning Muda & Memenuhi syarat \\
\hline Kandungan Lumpur & $4,5 \%$ & Maksimal $5 \%$ & Memenuhi syarat \\
\hline Bulk Specific SSD & $2,5484 \mathrm{gr} / \mathrm{cm}^{3}$ & $2,5-2,7 \mathrm{gr} / \mathrm{cm}^{3}$ & Memenuhi syarat \\
\hline
\end{tabular}

Pengujian agregat kasar berupa pengujian absorbtion, apparent specific gravity, bulk specific gravity, bulk spesific SSD, dan keausan agregat. Hasil pengujian ditampilkan dalam Tabel 2.

Table 2. Hasil Pengujian Agregat Kasar

\begin{tabular}{lccc}
\hline \multicolumn{1}{c}{ Jenis Pengujian } & Hasil Pengujian & Standar & Kesimpulan \\
\hline Absorbtion & $2,1 \%$ & - & - \\
\hline Apparent Specific Gravity & $2,6478 \mathrm{gr} / \mathrm{cm}^{3}$ & - & - \\
\hline Bulk. Specific Gravity & $2,5084 \mathrm{gr} / \mathrm{cm}^{3}$ & - & - \\
\hline Bulk Specific SSD & $2,5610 \mathrm{gr} / \mathrm{cm}^{3}$ & $2,5-2,7 \mathrm{gr} / \mathrm{cm}^{3}$ & Memenuhi syarat \\
\hline
\end{tabular}




\begin{tabular}{|c|c|c|c|c|c|c|}
\hline \multicolumn{3}{|c|}{ Keausan Agregat } & $92 \%$ & $<50 \%$ & & hi syarat \\
\hline \multicolumn{7}{|c|}{$\begin{array}{l}\text { Pengujian baja berupa kuat tarik baja. Sampel uji baja yang digunakan adalah baja polos berdiameter } 16 \mathrm{~mm} \\
\text { dengan panjang } 30 \mathrm{~cm} \text { dan telah dibubut sepanjang Lo } 6,5 \mathrm{~cm} \text { dengan diameter } 13 \mathrm{~mm} \text {. Hasil pengujian dit- } \\
\text { ampilkan dalam Tabel } 3 \text {. }\end{array}$} \\
\hline \multicolumn{7}{|c|}{ Tabel 3. Hasil Pengujian Kuat Tarik Baja Ø16 mm } \\
\hline $\begin{array}{c}\text { Benda } \\
\text { Uji }\end{array}$ & $\begin{array}{c}\mathrm{D} \\
(\mathrm{mm})\end{array}$ & $\begin{array}{c}\text { As } \\
\left(\mathrm{mm}^{2}\right)\end{array}$ & $\mathbf{P}_{\text {leleh }}(\mathbf{N})$ & $\mathbf{P}_{\text {maks }}(\mathbf{N})$ & Fy (MPa) & $\begin{array}{c}\mathrm{Fu} \\
(\mathrm{MPa})\end{array}$ \\
\hline A & 16 & \multirow{2}{*}{132,73} & 52514.20 & 80300 & 395,64 & 604,97 \\
\hline $\mathrm{B}$ & 16 & & 54453,42 & 83740 & 410,25 & 630,89 \\
\hline \multicolumn{5}{|c|}{ Rata-rata } & 402,95 & 617.93 \\
\hline
\end{tabular}

\section{Hasil Pengujian Beton Segar}

Pengujian beton segar HVFA-SCC kadar fly ash 50\% berupa pengujian Flow Table, L-Box, dan V-Funnel berdasarkan syarat dari EFNARC. Pengujian beton segar beton normal berupa pengujian slump berdasarkan syarat dari PBI 1971. Hasil pengujian ditampilkan dalam Tabel 4 hingga Tabel 6.

Tabel 4. Hasil Pengujian Flow Table Test HVFA-SCC 50\%

\begin{tabular}{|c|c|c|c|c|c|c|c|}
\hline \multirow{3}{*}{ Kode } & \multicolumn{4}{|c|}{ Flow Table Test } & \multirow{2}{*}{\multicolumn{3}{|c|}{$\begin{array}{l}\text { Syarat menurut } \\
\text { EFNARC }\end{array}$}} \\
\hline & \multicolumn{3}{|c|}{ Diameter } & \multirow{2}{*}{$\begin{array}{c}\text { Waktu } \\
t_{50} \\
(\mathrm{dt})\end{array}$} & & & \\
\hline & $\begin{array}{c}\mathrm{d} 1 \\
(\mathrm{~mm})\end{array}$ & $\begin{array}{c}\mathrm{d} 2 \\
(\mathrm{~mm})\end{array}$ & $\begin{array}{l}d_{\text {rata-rata }} \\
(\mathrm{mm})\end{array}$ & & $\begin{array}{l}T_{50} \\
\text { (s) }\end{array}$ & $\begin{array}{l}d_{\text {rata-rata }} \\
(\mathrm{mm})\end{array}$ & Keterangan \\
\hline $\begin{array}{c}\text { HVFA } \\
50 \%\end{array}$ & 700 & 700 & 700 & 3,11 & $2-5$ & $650-800$ & Memenuhi \\
\hline
\end{tabular}

Table 5. Hasil Pengujian L-Box HVFA-SCC 50\%

\begin{tabular}{cccccc}
\hline \multirow{2}{*}{ Kode } & \multicolumn{5}{c}{ L-Box Type } \\
\cline { 2 - 6 } & $\begin{array}{c}\mathbf{h}_{1} \\
(\mathbf{m m})\end{array}$ & $\begin{array}{c}\mathbf{h}_{\mathbf{2}} \\
(\mathbf{m m})\end{array}$ & $\mathbf{h}_{2} / \mathbf{h}_{1}$ & $\begin{array}{c}\text { Syarat } \\
\left(\mathbf{h}_{2} / \mathbf{h}_{\mathbf{1}}\right)\end{array}$ & Keterangan \\
\hline HVFA 50\% & 90 & 85 & 0,9444 & $0,8-1,0$ & Memenuhi \\
\hline \multicolumn{7}{c}{ Tabel 6. Hasil Pengujian } & $V$-Funnel & HVFA-SCC 50\% & & \\
\hline Kode & $\mathbf{T}(\mathbf{d t})$ & Syarat $\mathbf{( d t )}$ & Keterangan \\
\hline HVFA 50\% & 9,57 & $8-12$ & Memenuhi \\
\hline
\end{tabular}

Pengujian slump pada beton normal diperoleh nilai 10,5 cm. Berdasarkan PBI 1971, syarat nilai slump beton normal adalah 7,5-15 cm. Maka, hasil pengujian memenuhi syarat.

\section{Hasil Pengujian Kapasitas Geser Balok}

Pada pengujian balok beton bertulang HVFA-SCC 50\% dan balok beton normal mengalami keruntuhan balok akibat gagal geser, yaitu kapasitas geser balok lebih kecil dibandingkan dengan kapasitas lenturnya. Hubungan beban dan lendutan rata-rata hasil pengujian kapasitas geser balok beton bertulang HVFA-SCC $50 \%$ dan balok beton bertulang normal ditampilkan dalam gambar 3 dan 4 . 


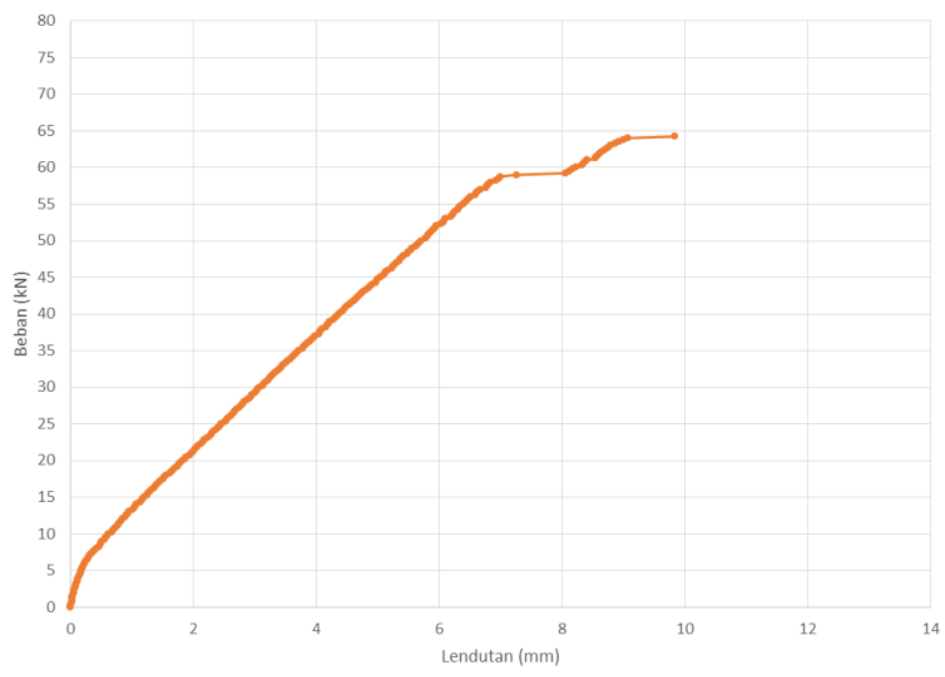

Gambar 3. Hubungan Beban-Lendutan Balok Beton Bertulang HVFA-SCC 50\%

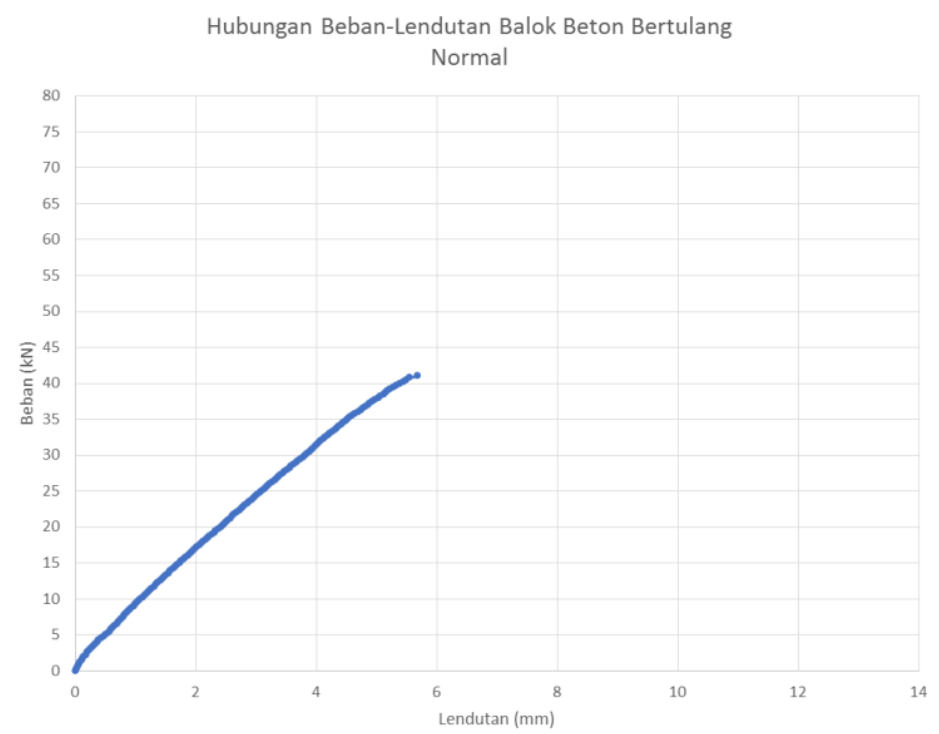

Gambar 4. Hubungan Beban-Lendutan Balok Beton Bertulang Normal

Berdasarkan grafik hubungan beban-lendutan, balok HVFA-SCC 50\% memiliki nilai beban maksimum 64,250 $\mathrm{kN}$ dan lendutan maksimum $9,843 \mathrm{~mm}$ yang lebih besar dibandingkan balok beton normal dengan nilai beban maksmimum 41,000 kN dan lendutan maksimum 5,675 mm.

Pada balok HVFA-SCC 50\% mengalami diagonal cracking strength sebelum ultimate strength, sedangkan pada balok beton normal langsung terjadi ultimate strength (diagonal cracking strength dianggap sama dengan nilai ultimate strength).

Dari data diatas didapatkan rata-rata gaya geser balok HVFA-SCC $50 \%$ adalah $32,125 \mathrm{kN}$ dan balok beton normal 20,500 kN. Hal ini membuktikan bahwa sifat fly ash mampu meningkatkan nilai daktilitas pada beton.

\section{SIMPULAN}

Dari penelitian ini dapat diambil beberapa kesimpulan sebagai berikut :

1. Beban dan lendutan yang dapat diterima pada balok HVFA-SCC 50\% lebih besar dibandingkan dengan balok beton normal, yaitu beban sebesar $64,250 \mathrm{kN}$ dan lendutan $9,843 \mathrm{~mm}$ untuk HVFA-SCC 50\%, sedangkan untuk beton normal beban sebesar $41,000 \mathrm{kN}$ dan kendutan 5,675 $\mathrm{mm}$ 
2. Kapasitas geser balok HVFA-SCC 50\% lebih besar dibandingkan dengan balok beton normal, yaitu 32,125 $\mathrm{kN}$ dibanding $20,500 \mathrm{kN}$.

\section{UCAPAN TERIMAKASIH}

Penulis mengucapkan rasa terima kasih kepada kepada Bapak Agus Setiya Budi, S.T., M.T. dan Bapak Dr. Eng. Halwan Alfisa Saifullah, S.T., M.T. selaku pembimbing yang dengan penuh kesabaran telah memberi materi dan pemahaman sehingga menyempurnakan penyusunan. Rasa terima kasih penulis sampaikan kepada tim Gabungan Super selaku tim kerja bekerja keras dalam penelitian ini.

\section{REFERENSI}

EFNARC. 2002. The European Guidelines for Self-Compacting Concrete Specification, Production and Use. The European Federation of Specialist Construction Chemicals and Concrete Systems.

EFNARC. 2005. The European Guidelines for Self-Compacting Concrete Specification, Production and Use. The European Federation of Specialist Construction Chemicals and Concrete Systems.

F. Ortiz Navas, Juan N.G., G. Leiva H., P. Serna, E. Cuenca. 2018. An Experimental Study on the Shear behaviour od Reinforced Concrete Beams With Macro-Synthetic Fibres. Construction and Building Materials 169 (2018).

Henry Apriyatno. 2010. Kapasitas geser Balok Beton Bertulang Dengan Polypropylene Fiber Sebesar 4\% Dari Volume Beton. Universitas Negeri Semarang.

James G. MacGregor. Reinforced Concrete Mechanics and Design. USA.

Kukun Rusyandi, dkk. 2012. Perancangan Beton Self Compacting Concrete (Beton Memadat Sendiri) Dengan Penambahan Fly Ash dan Structuro. Garut.

Laksmi Irianti. 2010. Kapasitas Ultimit dan Kapasitas Geser balok Beton Bertulang Mutu Tinggi Beragregat Batu Putih. Bandar Lampung.

Putut Sugianto. 2018. Kapasitas Lentur Balok Beton Bertulang High Volume Fly Ash Self Compacting Concrete (HVFASCC) Umur 28 Hari, Skripsi, Program Studi Teknik. Sipil Universitas Sebelas Maret. Surakarta.

SK SNI T-15-1991-03. 1991. Tata Cara Perbitungan Struktur Beton Untuk Bangunan Gedung. Bandung.

Stephen P. Timoshenko, James M. Gere. Mekanika Bahan Jilid 1. Jakarta.

Van Piseth. 2015. Effect of Loading Rates on Shear Perfomance of RC Beams. Graduate School of Engineering Civil and Environmental Engineering, Hiroshima University.

Wiryanto Dewobroto. 2005. Simulasi Keruntuhan Balok Beton Bertulang Tanpa Sengkang Dengan ADINATM. Prosiding Seminar Nasional "Rekayasa Material dan Konstruksi Beton 2005", Jurusan Teknik Sipil ITENAS 4 Juni 2005. 